\title{
Treatment of acute asthmatic exacerbations with an increased dose of inhaled steroid
}

\author{
J Garrett, S Williams, C Wong, D Holdaway
}

Department of Paediatrics and Child Health, Dunedin School of Medicine, PO Box 913, University of Otago Medical School, Dunedin, New

Zealand

J Garrett

Department of Preventive and Social Medicine, Dunedin School of Medicine $\mathrm{S}$ Williams

Department of Respiratory Medicine, Dunedin School of Medicine

C Wong

Department of Paediatrics and Child

Health, Dunedin School of Medicine D Holdaway

Correspondence to: Professor Holdaway.

\begin{abstract}
Objective-To investigate the efficacy of an increased dose of inhaled steroid used within the context of an asthma self management plan for treating exacerbations of asthma.

Design-Randomised, double blind, placebo controlled, crossover trial.

Methods-Twenty eight children aged 6-14 years with asthma of mild to moderate severity were studied for six months. Eighteen pairs of exacerbations were available for analysis, during which subjects took an increased dose of inhaled steroids or continued on the same dose. Results-There was no significant difference between increasing inhaled steroids or placebo on morning or evening peak expiratory flow rates (PEFRs), diurnal peak flow variability, or symptom scores in the two weeks following an asthma exacerbation. Difference $(95 \%$ confidence intervals) in baseline PEFR on days 1-3 were $3.4 \%(-3.5 \%$ to $10.4 \%)$ and $-0.9 \%$ $(-4.7 \%$ to $2.9 \%)$ for inhaled steroid and placebo, respectively. Spirometric function and the parents' opinion of the effectiveness of asthma medications at each exacerbation were also not significantly different between inhaled steroid or placebo.

Conclusion-This study suggests that increasing the dose of inhaled steroids at the onset of an exacerbation of asthma is ineffective and should not be included in asthma self management plans.

(Arch Dis Child 1998;79:12-17)
\end{abstract}

Keywords: asthma; inhaled steroids; self management plan; randomised control trial

The 1993 British Thoracic Society asthma management guidelines ${ }^{1}$ stated that although patients might be advised to increase their dose of inhaled steroids at the first sign of a cold or of asthma deterioration, there was no corroborative evidence from trials for the effectiveness of such an approach. A 1995 review of these guidelines ${ }^{2}$ reiterated the lack of published trials showing any benefit from this action. This observation has been made in other consensus documents. ${ }^{3}$

Although no trials have specifically investigated the use of an increased dose of inhaled steroids in the context of an asthma self management plan, three groups have looked at using intermittent courses of inhaled steroids for treating a deterioration of asthma. Wilson and Silverman ${ }^{4}$ found that treating acute attacks of asthma in 24 preschool children with $2.25 \mathrm{mg}$ of beclomethasone dipropionate each day for five days resulted in decreased severity but not decreased duration of asthma symptoms. Parents of children in the study showed a blinded preference for steroid treatment over placebo. Only five of the children in this trial were taking inhaled steroid prophylaxis on recruitment, four used sodium cromoglycate, and 15 had no prophylactic asthma medications. Connett and Lenney ${ }^{5}$ examined the effectiveness of inhaled budesonide at preventing virus induced asthma attacks in 32 preschool children. The children took inhaled budesonide $(800 \mu \mathrm{g})$ twice a day (increased to $1600 \mu \mathrm{g}$ if taken via a spacer) at the onset of upper respiratory symptoms, which usually precipitated an asthma attack. Treatment continued until the child was asymptomatic, or for seven days. This resulted in a significant reduction in the day and night time symptom scores for wheeze in the week following the onset of the attack. Once again, parents indicated a blinded preference for the active treatment. There was no reduction in the severity of cough, duration of any of the asthma symptoms, or in bronchodilator usage. None of the children in this trial had received previous prophylactic treatment. More recently, Svedmyr et al examined the effect of using a nine day reducing dose of inhaled budesonide to treat acute deterioration of asthma caused by upper respiratory tract infections in 26 children aged between 3 and 10 years. ${ }^{6}$ Active treatment resulted in significantly higher peak expiratory flow rates (PEFRs) in the period following an exacerbation. None of the children in this study used regular inhaled steroid prophylaxis.

Despite the lack of published evidence, a step involving an increased dose of inhaled steroids is a common component of asthma self management plans. It has been shown that $95 \%$ of general practitioners and $57 \%$ of paediatricians and paediatric registrars use such a treatment approach. ${ }^{7}$

Several trials have shown that self management plans are effective in the management of both adult ${ }^{8-10}$ and childhood ${ }^{112}$ asthma and most of these have used an action plan with a step involving an increased dose of inhaled steroid. However, it is not possible to determine from these studies the relative contribution of individual components of a self management plan. The objective of our study was to determine the effect of an increased dose of inhaled steroids on acute exacerbations of asthma in children, within the context of an asthma self management plan. 
Table 1 Symptom scoring explanation as provided to study participants

\begin{tabular}{|c|c|c|}
\hline Symptom & Score & Description \\
\hline \multirow[t]{4}{*}{ Night wheeze } & 0 & None \\
\hline & 1 & $\begin{array}{l}\text { Slight—slept well but slightly } \\
\text { wheezy }\end{array}$ \\
\hline & 2 & $\begin{array}{l}\text { Moderate-sleep disturbed by } \\
\text { wheeze }\end{array}$ \\
\hline & 3 & $\begin{array}{l}\text { Severe-awake most of the } \\
\text { night }\end{array}$ \\
\hline \multirow[t]{4}{*}{ Night cough } & 0 & None \\
\hline & 1 & $\begin{array}{l}\text { Slight-slept well but cough at } \\
\text { times }\end{array}$ \\
\hline & 2 & $\begin{array}{l}\text { Moderate-sleep disturbed by } \\
\text { cough }\end{array}$ \\
\hline & 3 & $\begin{array}{l}\text { Severe-awake most of the } \\
\text { night }\end{array}$ \\
\hline \multirow[t]{4}{*}{ Day wheeze } & 0 & None \\
\hline & 1 & $\begin{array}{l}\text { Less than } 3 \text { times a day, brief } \\
\text { and helped by inhalers }\end{array}$ \\
\hline & 2 & $\begin{array}{l}\text { More than } 3 \text { times a day, brief } \\
\text { and helped by inhalers }\end{array}$ \\
\hline & 3 & $\begin{array}{l}\text { Persistent symptoms lasting } \\
\text { longer than } 2 \text { hours }\end{array}$ \\
\hline \multirow[t]{4}{*}{ Day cough } & 0 & None \\
\hline & 1 & $\begin{array}{l}\text { Less than } 3 \text { times a day, brief } \\
\text { and helped by inhalers }\end{array}$ \\
\hline & 2 & $\begin{array}{l}\text { More than } 3 \text { times a day, brief } \\
\text { and helped by inhalers }\end{array}$ \\
\hline & 3 & $\begin{array}{l}\text { Persistent symptoms lasting } \\
\text { longer than } 2 \text { hours }\end{array}$ \\
\hline \multirow[t]{3}{*}{ Activities } & 0 & No limitation \\
\hline & 1 & $\begin{array}{l}\text { Any limitation-for example, } \\
\text { exercise induced wheeze or } \\
\text { cough }\end{array}$ \\
\hline & 2 & $\begin{array}{l}\text { Daily routine modified-for } \\
\text { example, missed school or } \\
\text { exercise }\end{array}$ \\
\hline
\end{tabular}

\section{Patients and methods}

This study was a randomised, double blind, placebo controlled, crossover trial. We aimed to recruit a sample of 30 children with asthma of mild to moderate severity. To be eligible, a child had to be aged between 6 and 14 years and currently on inhaled steroid prophylaxis (not exceeding $800 \mu \mathrm{g} /$ day). Children were excluded if any of the following applied: (1) they were taking oral steroids, sodium cromoglycate, or long acting $\beta_{2}$ agonists; (2) they had had any previous intensive care unit admissions, recent inpatient care for asthma, or any change in their dose of inhaled steroids in the past two months; or (3) they had any concurrent illness. Subjects were recruited through the paediatric outpatient department, the department of respiratory medicine, and a local general practice.

Following recruitment, participants entered a two week run in period during which they were required to use beclomethasone dipropionate via a metered dose inhaler and spacer (Volumatic; Allen and Hanburys, Middlesex, UK) and a salbutamol metered dose inhaler. This necessitated a change for those children not already using these agents or delivery devices. Because beclomethasone dipropionate and budesonide have been shown to be of similar efficacy, ${ }^{13}{ }^{14}$ the child's daily dose of inhaled steroids was not changed. During the second week of the run in period, the children completed a daily asthma diary in which they recorded morning and evening PEFRs measured on a mini-Wright peak flow meter, daytime and night time symptom scores of cough and wheeze, a daily activities symptom score, daily asthma medication use, and infor-
Table 2 Demographic and baseline data for study participants

\begin{tabular}{lll}
\hline & $\begin{array}{l}\text { 28 children } \\
\text { recruited }\end{array}$ & $\begin{array}{l}\text { 18 children in the } \\
\text { final analysis }\end{array}$ \\
\hline Age (years) & $9.3(2.6)$ & $8.2(2.0)$ \\
Sex (male/female) & $19 / 9$ & $12 / 6$ \\
Height (cm) & $134.3(13.6)$ & $129.3(11.6)$ \\
Weight (kg) & $33.0(9.7)$ & $29.9(7.4)$ \\
$\begin{array}{l}\text { Baseline PEFR } \\
\quad \% \text { predicted) }\end{array}$ & $100(11)$ & $99(10)$ \\
$\begin{array}{l}\text { Baseline FEV } \\
\text { Baseline FVC (\% predicted) }\end{array}$ & $99(12)$ & $99(13)$ \\
$\begin{array}{l}\text { Baseline FEF } \\
\quad \% \text { predicted) }\end{array}$ & $110(15)$ & $108(15)$ \\
$\quad$ & $89(21)$ & $93(23)$ \\
\hline
\end{tabular}

Values are mean (SD) except for sex.

mation about the presence of an upper respiratory tract infection or any other illness. Symptom scores were recorded on a scale from 0 to 3 (table 1). Participants were instructed to record their PEFR as the best of three prebronchodilator standing attempts. Information from the diary was used to calculate baseline PEFR and bronchodilator requirement. Spirometry measurements were made at the end of the run in period using a portable spirometer (Vitalograph-Compact; Vitalograph Ltd, Buckingham, UK), which was calibrated before each test with a 1 litre syringe (Vitalograph Precision Calibrating Syringe; Vitalograph Ltd). Forced expiratory volume in one second $\left(\mathrm{FEV}_{1}\right)$, forced vital capacity (FVC), and forced expiratory fraction $\left(\mathrm{FEF}_{25}\right.$ 75) were recorded as the best of three attempts performed with the subject standing.

Each child received a three zone asthma action plan that was individualised according to the baseline values obtained during the run in period. In the "green zone" represented by a PEFR above $80 \%$ of baseline and an absence of symptoms, the child used only their

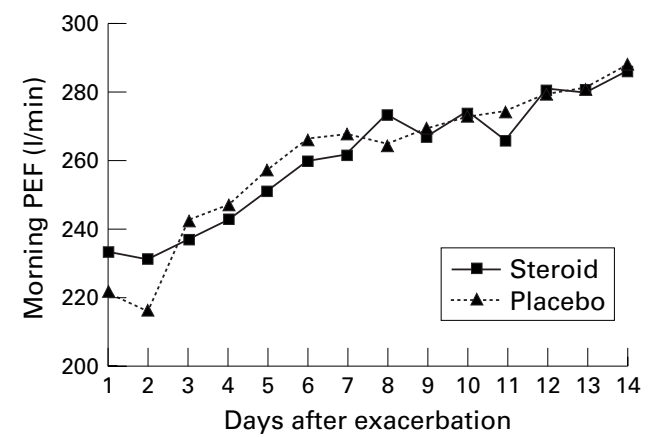

Figure 1 Morning peak expiratory flow (PEF) rates for patients taking increased dose of inhaled steroid or placebo.

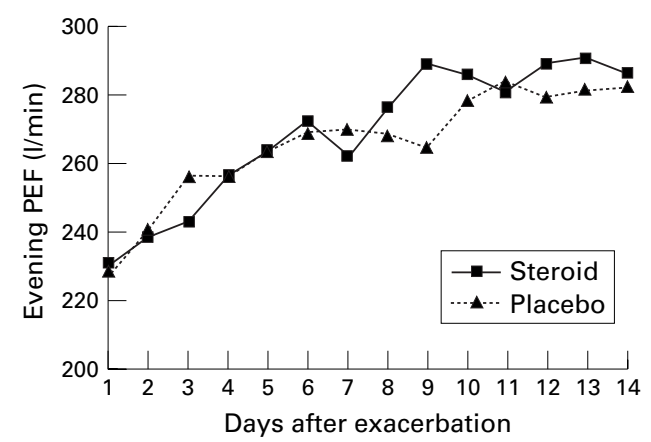

Figure 2 Evening peak expiratory flow (PEF) rates for patients taking increased dose of inhaled steroid or placebo. 


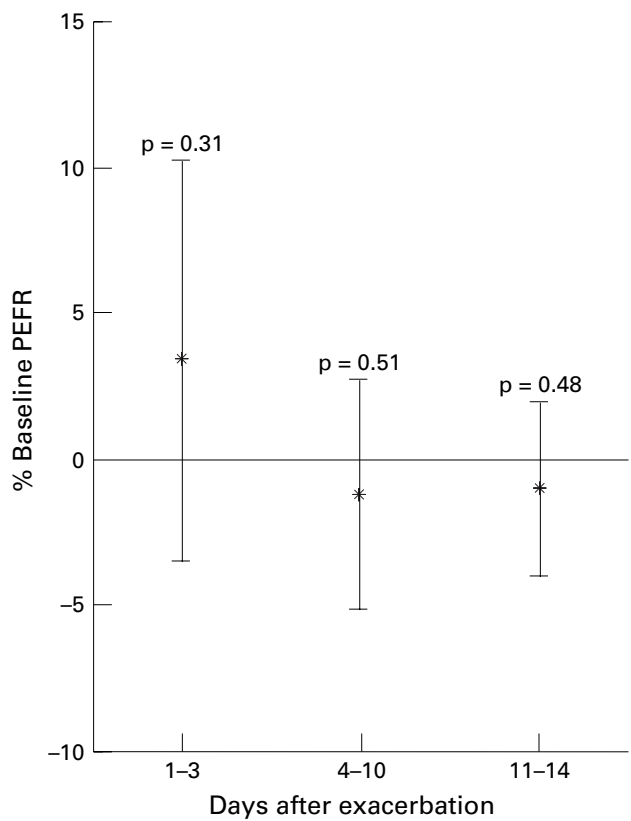

Figure 3 Difference (steroid - placebo) and 95\% CI for mean morning peak expiratory flow rates (PEFR) expressed as a percentage of baseline PEFR $(n=18)$.

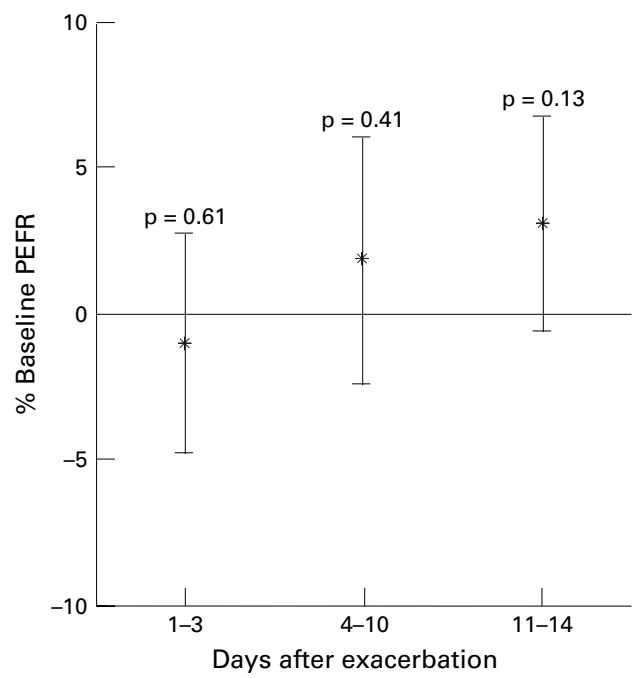

Figure 4 Difference (steroid - placebo) and 95\% CI for mean evening peak expiratory flow rates (PEFR) expressed as a percentage of baseline PEFR $(n=18)$.

maintenance medications. Entry into the "orange zone" occurred if the child's PEFR dropped below $80 \%$ of baseline for 24 hours or more, or they were woken at night with a cough or wheeze, or their bronchodilator requirement doubled. Meeting any one of these three criteria constituted an asthmatic exacerbation. When this occurred, the child used a study inhaler in addition to their maintenance beclomethasone. This blinded inhaler contained either beclomethasone or placebo, so that the child received either a double dose of beclomethasone or continued on their maintenance dose. The study inhaler was used for three days and during this time the child was visited at home, where their condition was checked and spirometry was performed. After three days, the child either returned to the "green zone" of their asthma action plan, or received definitive treatment following examination by a paediatrician if their exacerbation had not resolved. One week after the start of the exacerbation, the child was reviewed in the paediatric outpatients department and spirometry was repeated. If at any time during the study, the child's PEFR dropped below $60 \%$ of baseline, the child entered the "red zone" of their action plan, they were seen by a paediatrician, and received definitive treatment for their asthma. Each child followed this action plan for six months or until they had four exacerbations, all the time filling out the daily asthma diary. After stratification for age and sex, the children were randomised by the hospital pharmacist to one of two possible treatment sequences for serial exacerbations, placebo then steroid, or steroid then placebo. The investigators were blinded to this allocation.

Ethical approval was granted by the Southern Regional Health Authority ethics committee and all participants and their parents gave informed consent to participation.

\section{ANALYSIS}

The outcome measures used in the study were morning and evening PEFR; diurnal PEFR variability, calculated as the (highest-lowest) PEFR/highest PEFR; morning and evening symptom scores of cough and wheeze; an activity symptom score; and spirometric function including $\mathrm{FEV}_{1}, \mathrm{FVC}$, and $\mathrm{FEF}_{25-75}$ recorded during the run in period, during the exacerbation home visit, and one week after an exacerbation. Parents recorded an opinion score of the effectiveness of the study inhaler on a visual analogue scale that ranged from -3 (made asthma worse) through to +3 (made asthma better). Adverse events such as hospitalisation or oral steroid requirement were recorded.

Data from the two week period immediately following an exacerbation were analysed. For the PEFR and symptom scores the data were divided into three periods: days $1-3$ of the exacerbation, during which time the study inhaler was being used, days 4-10, and days 11-14, and the mean values for each outcome measure were calculated. A comparison between inhaled steroid and placebo treatment was made using the SAS procedure general linear models ${ }^{15}$ and the method described by Senn. ${ }^{16}$ Differences and 95\% confidence intervals are presented for each period. Spirometric function was analysed in a similar way to the PEFR and symptom score data. Parent's opinion scores for each treatment were compared using the Student's $t$ test. The data were analysed for a period effect.

\section{Results}

Twenty eight children were recruited, with the demographic and baseline spirometric characteristics as outlined in table 2. During the study, there were 49 asthma exacerbations: seven children had no exacerbations, three children had one exacerbation, nine children had two exacerbations, eight children had three exacerbations, and one child had four exacerbations. Only those with completed pairs of 
Table 3 Diurnal variation difference, expressed as steroid - placebo

\begin{tabular}{|c|c|c|c|c|}
\hline \multirow[b]{2}{*}{ Days postexacerbation } & \multicolumn{2}{|c|}{ Mean diurnal variation } & \multirow[b]{2}{*}{ Difference \% (95\% CI) } & \multirow[b]{2}{*}{ p value } \\
\hline & Steroid & Placebo & & \\
\hline $1-3$ & 8.2 & 11.5 & $-3.3(-7.7$ to 1.1$)$ & 0.13 \\
\hline $4-10$ & 9.0 & 7.2 & $1.8(-0.5$ to 4.1$)$ & 0.13 \\
\hline $11-14$ & 5.5 & 4.5 & $1.0(-1.0$ to 3.0$)$ & 0.38 \\
\hline \multicolumn{5}{|c|}{ Diurnal variation is (highest - lowest)/highest PEFR. } \\
\hline \multicolumn{5}{|c|}{$\begin{array}{l}\text { Table } 4 \text { Symptom scores for steroid and placebo treatment with the difference (steroid- } \\
\text { placebo) and } 95 \% \text { confidence intervals of the difference }\end{array}$} \\
\hline \multirow[b]{2}{*}{ Symptom } & \multicolumn{2}{|c|}{ Mean score } & \multirow[b]{2}{*}{ Difference $(95 \%$ CI) } & \multirow[b]{2}{*}{$p$ value } \\
\hline & Steroid & Placebo & & \\
\hline \multicolumn{5}{|l|}{ Night wheeze } \\
\hline Days $1-3$ & 0.59 & 0.65 & $-0.06(-0.39$ to 0.27$)$ & 0.80 \\
\hline Days $4-10$ & 0.22 & 0.33 & $-0.11(-0.32$ to 0.10$)$ & 0.34 \\
\hline Days $11-14^{\star}$ & 0.19 & 0.21 & $-0.02(-0.21$ to 0.17$)$ & 0.97 \\
\hline \multicolumn{5}{|l|}{ Night cough } \\
\hline Days $1-3$ & 1.20 & 0.97 & $0.23(-0.14$ to 0.60$)$ & 0.24 \\
\hline Days $4-10$ & 0.61 & 0.45 & $0.17(-0.19$ to 0.53$)$ & 0.33 \\
\hline Days $11-14$ & 0.39 & 0.26 & $0.13(-0.19$ to 0.45$)$ & 0.34 \\
\hline \multicolumn{5}{|l|}{ Day wheeze } \\
\hline Days $1-3$ & 0.65 & 0.82 & $-0.17(-0.55$ to 0.21$)$ & 0.41 \\
\hline Days $4-10$ & 0.23 & 0.32 & $-0.09(-0.26$ to 0.08$)$ & 0.36 \\
\hline Days $11-14$ & 0.21 & 0.17 & $0.04(-0.16$ to 0.24$)$ & 0.57 \\
\hline \multicolumn{5}{|l|}{ Day cough } \\
\hline Days $1-3$ & 1.20 & 0.97 & $0.23(-0.36$ to 0.82$)$ & 0.42 \\
\hline Days $4-10$ & 0.61 & 0.45 & $0.16(-0.26$ to 0.58$)$ & 0.43 \\
\hline Days 11-14 & 0.56 & 0.26 & $0.30(-0.02$ to 0.62$)$ & 0.06 \\
\hline \multicolumn{5}{|l|}{ Activities } \\
\hline Days $1-3^{\star}$ & 0.50 & 0.69 & $-0.10(-0.48$ to 0.28$)$ & 0.27 \\
\hline Days $4-10^{\star}$ & 0.22 & 0.21 & $0.01(-0.25$ to 0.27$)$ & 0.96 \\
\hline Days $11-14$ & 0.24 & 0.06 & $0.18 \quad(0.07$ to 0.29$)$ & 0.05 \\
\hline
\end{tabular}

${ }^{\star}$ Based on 17 pairs of observations.

exacerbations were included in the final analysis (18). In those children having three exacerbations the third was not analysed. For the two week period following an exacerbation, the mean diary completion rate, expressed as the percentage of expected entries that were actually present, was $95 \%$. In 31 exacerbations $(86 \%)$, the study protocol was followed correctly. The five deviations from the protocol involved the study inhaler being used for an incorrect number of days. No significant period effect was detected.

PEAK EXPIRATORY FLOW RATE

The mean morning and mean evening PEFRs were similar for steroid and placebo treatments in the two weeks following an exacerbation (figs 1 and 2). A reduction in PEFR at the time of the exacerbation was evident, and showed a return towards baseline with time.

When the data were analysed for the three time periods, the differences between the treatments were not significant (figs 3 and 4 ). The diurnal variation in PEFR was similar for both groups (table 3).

SYMPTOM SCORES

There was no significant difference between treatments for any of the symptom scores, apart from days 11-14 in the activities score, where a difference in favour of placebo treatment was seen (table 4). Asthma symptoms were most prevalent at the start of the exacerbation and then returned towards the symptom free state with time. It was noted that, while not being significant, the symptom scores for wheeze were consistently in favour of the

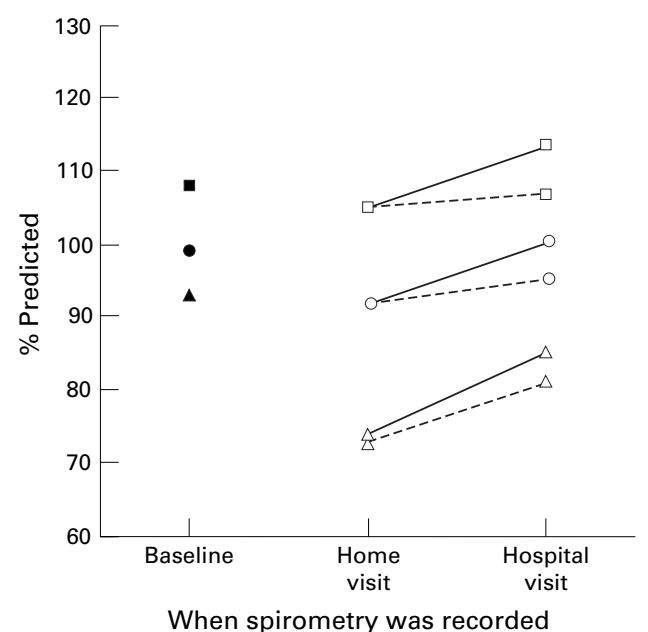

Figure 5 Spirometric function during steroid (solid line) and placebo (dashed line) treatment. Squares, FVC; Circles, $F E V_{1}$; Triangles, $F E F_{25-75}(n=18)$.

steroid, and those for cough were consistently in favour of the placebo.

SPIROMETRY

At the time of an exacerbation, spirometric function was reduced for both treatments for $\mathrm{FEV}_{1}, \mathrm{FVC}$, and $\mathrm{FEF}_{25-75}$ when compared with the baseline recordings. One week after the exacerbation, all measures returned towards baseline levels. There was no significant difference between the treatments for any of the spirometric parameters measured (fig 5).

PARENT'S OPINION SCORE

The mean parent's opinion score was 1.12 for the steroid and 1.18 for the placebo $(p=0.177)$. This is a positive opinion score for both treatments, although they did not differ.

ADVERSE EVENTS

During the study, two children required oral steroids for exacerbations of their asthma and on both occasions the study inhaler contained steroid. This number of events is too small to be significant. None of the children was hospitalised during the study.

In summary, there were small but not significant differences between steroid or placebo treatment for any of the outcome measures used, apart from the daily activities score on days $11-14$ of the exacerbation. We observed a deterioration in PEFR, symptoms, and spirometric function at the time of an exacerbation, which all returned towards baseline.

\section{Discussion}

We have conducted a trial investigating the role of an increased dose of inhaled steroids within the context of an asthma action plan. In our study a double dose of inhaled beclomethasone had no beneficial effect on an asthma exacerbation compared with placebo, and this is evidence against using such an approach in asthma management. This finding has several implications, but these should be applied with due consideration to the limitations of this study. 
The first criticism directed at many studies resulting in a negative outcome is that they lacked the power to detect an effect. Before commencing our study, we were unable to find any good data on which to perform power calculations and estimate sample size requirements and so we performed retrospective power calculations. Using the baseline PEFR data we can say that a sample of 28 children gave us an $80 \%$ chance of detecting a difference of 0.55 SD (5\% of baseline PEFR) at the $5 \%$ level of significance. The 18 pairs of exacerbations available for analysis were too few to detect the differences in any of the outcomes in our study. However, many of the differences between steroid and placebo treatment were small and below what we would regard as clinically significant. If we say that a clinically significant PEFR difference between a double dose of inhaled steroid and placebo is $10 \%$ of baseline PEFR then, according to our data, 17 pairs of exacerbation's would give an $80 \%$ chance of detecting this difference at the $5 \%$ level of significance. To detect a difference in symptom scores of 0.5 with similar power would require 23 pairs of exacerbations. We have been able to rule out a clinically significant difference between the two treatments. This information will be useful for the design of future studies.

In addition to enhancing power, larger numbers of children would have provided a more comprehensive sample of children with asthma. This study included only children with mild to moderate asthma, and we do not know whether exacerbations in children with severe asthma would respond differently to an increased dose of inhaled steroid. The natural history of an asthma exacerbation might differ with both the severity of the underlying condition and the trigger of the exacerbation, and more information about this could be gained from a larger study involving a variety of children with asthma.

The use of a double dose of inhaled steroids administered for only three days was a compromise between common practice and safety considerations. In New Zealand, it is most common for the dose of inhaled steroids to be doubled until the child's condition returns to normal. However, during this study the children were potentially receiving placebo treatment for an exacerbation. Continuing this treatment until they returned to baseline levels would have been inappropriate, and a period of three days was chosen to avoid compromising the childrens' safety. We do not know if a larger increase in inhaled steroids for a longer period would have been more effective, although several observations suggest that there would be no improvement in outcome. Three studies that investigated an increased dose of inhaled steroid $^{4-6}$ used larger increases for longer durations than we did, with only minimal benefit. We could not detect any difference between the two treatments during the first three days of the exacerbation, when the study inhaler was being used, and the maintenance of improvement shown after stopping either inhaled steroid or placebo suggests that extending the duration of treatment would have no effect on the natural history of an exacerbation. Oral steroids are known to be effective for treating acute severe exacerbations of asthma, ${ }^{17}$ and there is some evidence that high dose inhaled corticosteroid may be as effective as a course of oral corticosteroid in acute exacerbations of asthma in adults. ${ }^{18}$ However, the required dose in children may not be reliably achievable by the inhaled route, and would need to be shown to be superior in terms of side effects and cost effectiveness.

In our study, $95 \%$ of all the diary entries during an exacerbation period were completed and the study protocol was followed correctly in all but five exacerbations. We feel that these figures are reasonable, in that this was a practical study that was designed to reflect the reality of asthma treatment, in which compliance is often less than perfect. For this reason, we included the data from the five exacerbations where the protocol was not followed in the analysis. We did not scrutinise each exacerbation to determine whether the criteria for starting the study inhaler had been met, but allowed the children and their parents to make this decision based on the explanation they were given at the start of the study and the written information contained in their asthma action plan.

Although our study was placebo controlled, we do not know what effect no treatment would have on an asthma exacerbation. There might be a significant placebo effect involved. Examination of the children's asthma diaries for "missed" exacerbations in our study was not helpful in answering this question, but it would be useful to include a "no treatment arm" in future studies, although this would involve the institution of measures to ensure the safety of participants.

Our study suggests that the outcome from an acute asthmatic exacerbation is not improved by administration of an increased dose of inhaled steroids and that, therefore, this increase should not be included as a step in an asthma self management plan. This conclusion should be confirmed by a larger study, in which it would be appropriate to include a "no treatment" arm, in addition to the active and placebo treatment. There remains a need to investigate the most effective way to treat an asthma exacerbation and how to incorporate this into an action plan.

This project was supported by a grant from the Otago Division of the New Zealand Asthma Society. John Garrett was funded by a Jun Zealand Asthma Society. John Garret was funded by a Juni N New Z Hearch Council of New Zealand. Sheila Willims is also supported by the Health Research Council of New Zealand. We are particularly grateful to the children and the parents who participated in the trial.

1 British Thoracic Society, British Paediatric Association, Research Unit of the Royal College of Physicians of London, King's Fund Centre, National Asthma Campaign, et al. Guidelines on the management of asthma. Thorax 1993;48(suppl):S1-24.

2 British Thoracic Society, British Paediatric Association, Research Unit of the Royal College of Physicians of London, King's Fund Centre, National Asthma Campaign, et al. The British guidelines on asthma management. 1995 review and position statement. Thorax 1997;52(suppl S1-21.

3 Asher 1, Toop L, Mitchell E. Asthma in children: consensus on preventive management in New Zealand. $N Z \mathrm{Med} \mathcal{F}$ 1994;107:108-10. 
4 Wilson NM, Silverman M. Treatment of acute, episodic Wilson NM, Silverman M. Treatment of acute, episodic asthma in preschool children using intermittent high dose
inhaled steroids at home. Arch Dis Child 1990;65:407-10.

5 Connett G, Lenney W. Prevention of viral induced asthma Connett G, Lenney W. Prevention of viral induced asthma attacks $85-7$.

6 Svedmyr J, Nyberg E, Asbrink-Nilsson E, Hedlin G. Intermittent treatment with inhaled steroids for deterioration of asthma due to upper respiratory tract infections. Acta Paediatr 1995;84:884-8.

7 Garrett J, Williams S, Wong C, Holdaway D. Application of asthma action plans to childhood asthma: a national survey. N Z Med f 1997;110:308-10.

8 Beasley R, Cushing M, Holgate S. A self management plan in the treatment of adult asthma. Thorax 1989;44:200-4.

9 Lahdensuo A, Haahala T, Herrala J, et al. Randomised comparison of guided self management and traditional
treatment of asthma over one year. $B M \mathcal{F} 1996 ; 312: 748-52$.

10 D'Souza W, Burgess C, Ayson M, Crane J, Pearce N, Beasley R. Trial of a "credit card" asthma self management plan in a high risk group of patients with asthma. f Allergy Clin in a high risk group of patient
11 Gillies J, Barry D, Crane J, et al. A community trial of a written self management plan for children with asthma. $N$ written self management

12 Charlton 1, Antoniou A, Atkinson J, et al. Asthma at the interface: bridging the gap between general practice and a district general hospital. Arch Dis Child 1994;70:313-18.

13 Kerrebijn K. Use of topical corticosteroids in the treatment of childhood asthma. Am Rev Respir Dis 1990;141(suppl): S77-81.

14 Davies B. A comparison of beclomethasone dipropionate and budesonide in the treatment of asthma. Brf Clin Pharmacol 1993;47:87-93.

15 SAS Institute Inc. $S A S / S T A T$ user's guide. Version 6, 4th ed, Vol 2. Cary, North Carolina: SAS Institute, 1989.

16 Senn S. Cross-over trials in clinical research. Chichester: John Wiley and Sons Ltd, 1993.

17 Bames N. Effects of corticosteroids in acute severe asthma. Thorax 1992;47:582-3.

18 Levy M, Stevenson C, Maslen T. Comparison of short courses of oral prednisolone and fluticasone propionate in the treatment of adults with acute exacerbations of asthma in primary care. Thorax 1996;51:1087-92. 